\title{
ARTICLE OPEN \\ Opportunities to develop the professional role of community pharmacists in the care of patients with asthma: a cross-sectional study
}

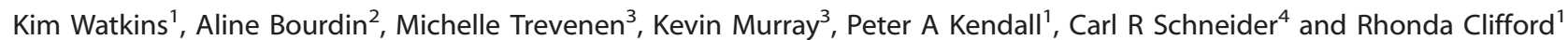

There are many indications in Australia and globally that asthma management is suboptimal. Ideally, patients need to proactively self-manage the condition with the support of health professionals. Community pharmacists are a highly accessible resource for patients but currently provide inconsistent services. General practitioners also face many barriers to the provision of chronic disease management for asthma patients. The aim of this research was to characterise patients with asthma who present to community pharmacy. The objective was to identify opportunities to develop the role of pharmacists in the context of the primary healthcare setting and in view of the needs of the patients they routinely encounter. The results of a comprehensive survey of 248 patients recruited from community pharmacies indicated there was discordance between patient perceptions of asthma control and actual asthma control. Almost half the patients surveyed had poorly controlled asthma, whereas almost three quarters perceived their asthma to be well or completely controlled. Fewer than $20 \%$ of patients were utilising written asthma action plans, and issues around quality use of medicines were identified. The significance of the incongruent perceptions regarding asthma control is that patients are unlikely to proactively seek intervention and support from healthcare professionals. Community pharmacists provide a significant opportunity to address these issues by direct intervention. There is scope to investigate pharmacists preparing written asthma action plans for patients, using software to monitor medication adherence and prescribe on-going medication. To maximise the potential of pharmacists, barriers to practice need to be identified and addressed.

npj Primary Care Respiratory Medicine (2016) 26, 16082; doi:10.1038/npjpcrm.2016.82; published online 24 November 2016

\section{INTRODUCTION}

Despite the important advances made in the past 30 years in the medical management of asthma, the condition remains suboptimally controlled and constitutes a significant health burden. ${ }^{1,2}$ Asthma has impacts at an individual and societal level, and has been a National Heath Priority Area in Australia since 1999. ${ }^{3}$

Currently, asthma is routinely managed in the primary-care setting by general practitioners (GPs). GPs are responsible for writing asthma action plans for patients and prescribing preventer medications (inhaled corticosteroids (ICSs)) to control the condition. However, deficiencies in the quality of care provided by GPs have been observed including, inadequate provision of written asthma action plans, lack of guideline compliant practice and suboptimal patient outcomes. ${ }^{4-6}$ One issue that impedes optimal asthma management by GPs is the lack of routine asthma visits by patients, ${ }^{4,7}$ limiting the opportunities for patient education and chronic disease management. GPs observe that patients present only at times of acute exacerbations of asthma. ${ }^{9}$ Meanwhile, community pharmacists are the most highly accessible primary-care health professionals, ${ }^{10}$ yet are an underutilised resource. ${ }^{11,12}$

Increasingly, there is evidence that indicates the potentially beneficial role that community pharmacists can have in reducing the burden of asthma. ${ }^{13-16}$ However, most of the research to date has been on guided screening and management programmes, undertaken as relatively short-term research interventions. ${ }^{13,14}$ These programmes often require specialised training and resources. There is a paucity of translational research in asthma that develops sustainable roles for community pharmacists that are widely implemented as part of 'routine practice' and embraced by the broader healthcare system. On the contrary, there is evidence to indicate that in 'routine practice', community pharmacists are not assessing, intervening or referring patients appropriately and are falling well short of their potential. ${ }^{17,18}$ Many barriers are impeding GPs and community pharmacists in the provision of quality, evidence-based care for asthma patients. ${ }^{6,19-21}$

In Australia, the unrealised potential and suboptimal practice by community pharmacists is particularly relevant because of legislation that permits asthma reliever medications to be provided by pharmacists without a prescription. Legally, pharmacists have the responsibility to assess patient therapeutic need and directly supervise the sale of asthma reliever medications under Schedule 3 'Pharmacist-Only' legislation. ${ }^{22}$ The effect of this legislation is that community pharmacists may be the only health professional in a position to regularly assess patients with asthma relying on reliever medications. Even patients using ICSs and/or other prescription medication have prescriptions dispensed by pharmacists on a monthly basis, whereas GPs and medical

\footnotetext{
${ }^{1}$ School of Medicine and Pharmacology, Centre for Optimisation of Medicines, Pharmacy, The University of Western Australia, Crawley, WA, Australia; ${ }^{2}$ Community Pharmacy, School of Pharmaceutical Sciences, University of Geneva, University of Lausanne, Geneva, Switzerland; ${ }^{3}$ Centre for Applied Statistics, The University of Western Australia, Crawley, WA, Australia and ${ }^{4}$ Faculty of Pharmacy, The University of Sydney, Camperdown, NSW, Australia.

Correspondence: K Watkins (kim.watkins@uwa.edu.au)

Received 27 January 2016; revised 4 October 2016; accepted 8 October 2016
} 
Table 1. Comparison of pharmacy characteristics between the pharmacies that agreed and refused to participate in the study

\begin{tabular}{lccccc}
\hline & \multicolumn{2}{c}{$\begin{array}{c}\text { Pharmacy } \\
\text { participated }\end{array}$} & & \multicolumn{2}{c}{$\begin{array}{c}\text { Pharmacy did } \\
\text { not participate }\end{array}$} \\
\cline { 2 - 3 } \cline { 6 - 7 } & $\mathrm{N}$ & $\%$ & & $\mathrm{~N}$ & $\%$ \\
\hline $\begin{array}{l}\text { Pharmacy location } \\
\text { Street }\end{array}$ & 12 & 40.00 & & 10 & 50.00 \\
$\quad$ Medical centre & 1 & 3.33 & & 5.00 \\
$\quad$ Shopping centre & 17 & 56.67 & & 45.00 \\
Pharmacy type & & & & \\
$\quad$ Independent & 12 & 40.00 & & 7 & 35.00 \\
$\quad$ Chain & 18 & 60.00 & & 13 & 65.00 \\
\hline
\end{tabular}

specialists are able to write a prescription for a 6-month supply and thus may only see the patient twice per year or less, depending upon medical adherence.

In recognition of the unique role that community pharmacists have in asthma management in Australia, the Pharmaceutical Society of Australia endorsed Guidelines for the provision of short-acting $\beta_{2}$-agonist as Pharmacist-Only medications (SABA guidelines). ${ }^{23}$ However, to develop sustainable roles for pharmacists and identify opportunities for screening, intervention or referral within the scope of routine practice, it is important to understand more about the needs of patients with asthma routinely presenting in community pharmacy. This includes patients obtaining prescriptions as well as those who may be self-managing with reliever medications. There is a need to understand the issues of patients seeking help and advice as well as those who do not acknowledge they have any issues with asthma and simply visit pharmacies as a retail destination. What are the characteristics of the asthma patient that the pharmacist encounters on a daily basis?

The aim of this research was to characterise patients with asthma who present to community pharmacy. The objective was to identify opportunities to develop the role of pharmacists in the context of the primary healthcare setting and in view of the needs of the patients they routinely encounter.

\section{RESULTS}

Pharmacy and patient numbers

A convenience sample of 50 community pharmacies were invited to participate in the research and 30 agreed to act as patient recruitment sites. Comparisons based on pharmacy location and pharmacy type did not suggest any non-response bias (Table 1). Six Master of Pharmacy students surveyed a total of 249 patients over the 2-month data collection period. The number of questionnaires completed in each pharmacy ranged between 0 and 17 with a mean of 8.3 surveys collected per pharmacy. One survey was excluded due to incomplete data leaving a total of 248 surveys.

\section{Demographics}

Sixty-seven percent of patients surveyed were females, and $72 \%$ of patients were born in Australia (Table 2). The survey included an age range of $18.5-93.9$ years with a median age of 48.8 years. Data on current employment status were pooled into employed (employed for wages and self-employed) and not employed (out of work and looking, out of work but not looking, homemaker, student, retired, unable to work).
Table 2. Patient demographics - counts and percentages of categorical patient demographic variables

\begin{tabular}{|c|c|c|}
\hline & $\mathrm{N}$ & $\%$ \\
\hline \multicolumn{3}{|l|}{ Gender } \\
\hline Male & 82 & 33.06 \\
\hline Female & 166 & 66.94 \\
\hline \multicolumn{3}{|l|}{ Age (years) } \\
\hline $18-49$ & 127 & 51.21 \\
\hline$\geqslant 50$ & 121 & 48.79 \\
\hline \multicolumn{3}{|l|}{ Country of birth } \\
\hline Australia & 179 & 72.18 \\
\hline Other & 69 & 27.82 \\
\hline \multicolumn{3}{|l|}{ Highest level of education } \\
\hline Up to year 12 & 130 & 52.42 \\
\hline Technical college/Bachelor/Post Graduate & 118 & 47.58 \\
\hline \multicolumn{3}{|l|}{ Current employment status } \\
\hline Employed & 121 & 48.79 \\
\hline Not employed & 127 & 51.21 \\
\hline \multicolumn{3}{|l|}{ Language primarily spoken at home } \\
\hline English & 239 & 96.37 \\
\hline Other & 9 & 3.63 \\
\hline \multicolumn{3}{|l|}{ Household size } \\
\hline Small household ( $<4$ occupants) & 186 & 75.00 \\
\hline Large household ( $\geqslant 4$ occupants) & 62 & 25.00 \\
\hline \multicolumn{3}{|l|}{ Income } \\
\hline Less than $\$ 80,000$ & 155 & 62.50 \\
\hline$\$ 80,000$ or more & 93 & 37.50 \\
\hline
\end{tabular}

Patient history and medication use

Of the 248 patients' surveys, 31 (12.5\%) perceived that they had a life-threatening attack in the past 5 years. Thirty-nine patients (15.7\%) owned a written asthma action plan to assist in management of their asthma (Table 3).

One hundred and eighty-one patients surveyed (73.0\%) were using a 'preventer' medication to treat their asthma. Fifty-five patients (22.2\%) were managing their asthma with a SABA alone and two patients $(0.8 \%)$ were using a SABA and long-acting $\beta_{2}$-agonist (LABA) as their only therapy (Table 4).

Of the 181 patients using ICS, 98 (54.14\%) had poorly controlled asthma. There were 148 patients using combination ICS and LABA, and $78(52.7 \%)$ of these had poorly controlled asthma (Table 5). Patients using their asthma reliever inhaler two or more times a week were significantly more likely to be using ICSs than patients not using their reliever that frequently (odds ratio $(O R=1.85,95 \%$ confidence interval $((\mathrm{Cl})=1.01-3.38, P=0.0449)$.

Table 6 gives a summary of the key results from each of the validated tools incorporated into the Asthma Questionnaire. ${ }^{24-30}$ Using the ACT, patients with a score of 20 or more are considered to have well-controlled asthma, whereas patients with a score of 19 or less are classified as having poor overall asthma control. In this survey, 120 patients $(48.4 \%)$ had poorly controlled asthma.

Factors influencing asthma control

Table 7 shows the regression analysis of factors affecting asthma control. Univariate analysis indicated that poor asthma control was significantly related to older age $(P=0.0068)$, poor quality of life $(P<0.0001)$, poor beliefs about ability to control asthma $(P<0.0001)$, use of ICS $(P=0.0033)$, smoking $(P=0.0189)$ and sinusitis $(P=0.0065)$. No relationships were demonstrated 
Table 3. Selected responses to patient history questions-counts and percentages of categorical patient history variables

\begin{tabular}{|c|c|c|}
\hline & $\mathrm{N}$ & $\%$ \\
\hline \multicolumn{3}{|c|}{ Symptoms or treatment for asthma in the past 12 months? } \\
\hline Yes & 232 & 93.55 \\
\hline No & 16 & 6.45 \\
\hline \multicolumn{3}{|c|}{ Asthma worse or out of control in the past 12 months? } \\
\hline Yes & 96 & 38.71 \\
\hline No & 152 & 61.29 \\
\hline \multicolumn{3}{|c|}{ Hospital admissions in the last 12 months? } \\
\hline Yes & 7 & 2.82 \\
\hline No & 241 & 97.18 \\
\hline \multicolumn{3}{|c|}{ Life-threatening asthma attack in past 5 years? } \\
\hline Yes & 31 & 12.50 \\
\hline No & 210 & 84.68 \\
\hline Not sure & 7 & 2.82 \\
\hline \multicolumn{3}{|c|}{ Days off work, study or usual activities because of asthma? } \\
\hline Yes & 52 & 20.97 \\
\hline No & 196 & 79.03 \\
\hline \multicolumn{3}{|c|}{ Lifestyle modifications due to asthma? } \\
\hline Yes & 110 & 44.35 \\
\hline No & 126 & 50.81 \\
\hline Not sure & 12 & 4.84 \\
\hline \multicolumn{3}{|c|}{ Written asthma action plan ownership? } \\
\hline Yes & 39 & 15.73 \\
\hline No & 209 & 84.27 \\
\hline \multicolumn{3}{|c|}{ Currently smoker? } \\
\hline Yes & 45 & 18.15 \\
\hline No & 203 & 81.85 \\
\hline \multicolumn{3}{|c|}{ Co-morbidities_hay fever? } \\
\hline Yes & 106 & 42.74 \\
\hline No & 142 & 57.26 \\
\hline \multicolumn{3}{|l|}{ Sinusitis? } \\
\hline Yes & 41 & 16.53 \\
\hline No & 207 & 83.47 \\
\hline \multicolumn{3}{|l|}{ Depression? } \\
\hline Yes & 51 & 20.56 \\
\hline No & 197 & 79.44 \\
\hline
\end{tabular}

between asthma control and knowledge scores or medication adherence scores. Ownership of a written asthma action plan, gender of the patient and concomitant hay fever were also not shown to be predictors of poor asthma control. Multivariate analysis demonstrated that the only significant relationship was between asthma quality of life and asthma control $(P<0.0001)$ where patients with higher scores in the AQLQ-S (indicating asthma has a greater negative impact on their quality of life) were significantly more likely to have poorly controlled asthma (for a one-point increase in AQLQ-S score: OR=22.4, $95 \% \mathrm{Cl}=9.3-53.9)$.

Factors influencing written asthma action plan ownership A significant positive relationship was found between use of ICS and ownership of a written asthma action plan (ICS use versus no ICS use: $\mathrm{OR}=2.87,95 \% \mathrm{Cl}=1.07-7.68, P=0.036)$. Variables such as age, sex and asthma knowledge had no relationship with written asthma action plan ownership.
Table 4. Patient current asthma medications

\begin{tabular}{|c|c|}
\hline Therapy & $\mathrm{N}(\%)$ \\
\hline $\begin{array}{l}\text { Patients not currently using any medication to control } \\
\text { asthma }\end{array}$ & $10(4.03)$ \\
\hline SABA as only therapy & $56(22.58)$ \\
\hline SABA and LABA as only therapy (without any ICS) & $2(0.81)$ \\
\hline Patients using ICS (with or without other medications) & $181(72.98)$ \\
\hline $\begin{array}{l}\text { Combination LABA/ICS (with or without other } \\
\text { medications) }\end{array}$ & $148(59.68)$ \\
\hline Cromogylycates $^{\mathrm{a}}$ & $3(1.21)$ \\
\hline Montelukast $^{\mathrm{a}}$ & $1(0.40)$ \\
\hline Theophyllines $^{\mathrm{a}}$ & $3(1.21)$ \\
\hline
\end{tabular}

Table 5. Asthma control and medication use

\begin{tabular}{|c|c|c|c|c|}
\hline & \multicolumn{4}{|c|}{ Asthma control } \\
\hline & \multicolumn{2}{|c|}{ Poorly controlled } & \multicolumn{2}{|c|}{ Well controlled } \\
\hline & $\mathrm{N}$ & $\%$ & $\mathrm{~N}$ & $\%$ \\
\hline \multicolumn{5}{|l|}{ On ICS } \\
\hline No & 22 & 32.84 & 45 & 67.16 \\
\hline Yes & 98 & 54.14 & 83 & 45.86 \\
\hline \multicolumn{5}{|c|}{ On ICS/LABA combination } \\
\hline No & 42 & 42.00 & 58 & 58.00 \\
\hline Yes & 78 & 52.70 & 70 & 47.30 \\
\hline
\end{tabular}

Factors influencing asthma attacks and emergency medical presentations

Patients with poor asthma control were significantly more likely to have had a 'life-threatening asthma attack' in the previous five years compared with those with good asthma control $(\mathrm{OR}=2.58$, $95 \% \mathrm{Cl}=1.07-6.22, P=0.035)$. Patients with a greater perceived ability to control asthma were significantly less likely to have had a 'life-threatening attack' in the previous 5 years compared with those with poorer perceived ability to control asthma (for a onepoint increase in Perceived Control of Asthma Questionnaire score: $\mathrm{OR}=0.90,95 \% \mathrm{Cl}=0.83-0.97, P=0.0039$ ).

Emergency medical presentations included urgent visits to a GP, Emergency Department (ED) or hospital admission, due to asthma getting worse or out of control, or having a lifethreatening attack. Patients with poor asthma control were significantly more likely to have had an emergency medical presentation compared with those with good control $(\mathrm{OR}=2.74$, $95 \% \mathrm{Cl}=1.59-4.71, P=0.0003)$. Patients with greater perceived ability to control asthma were significantly less likely to have an emergency medical presentation compared with those with poorer perceptions about the ability to control asthma (for a one-point increase in Perceived Control of Asthma Questionnaire score: $\mathrm{OR}=0.93,95 \% \mathrm{Cl}=0.88-0.98, P=0.0055$ ).

\section{DISCUSSION}

Main findings

This study achieved its aim to provide an understanding of the needs of patients with asthma in the community. It accomplished 
Table 6. Key results of individual validated tools from the Asthma Questionnaire

Asthma control (ACT_Asthma Control Test) $)^{24,25}$

Mean score of ACT

Median score of ACT

Number of patients with poor asthma control

Number of patients who rated their asthma as being well controlled or completely

controlled in the previous 4 weeks

Number of patients who thought their asthma was well or completely controlled who were

assessed as having good asthma control

Patients woken at night by asthma in the previous 4 weeks

Patients experiencing shortness of breath at least once in the previous 4 weeks

Asthma quality of life (AQLQ-S-Asthma Quality of Life Questionnaire-Sydney) $)^{26}$

Mean score of AQLQ-S (adjusted scale 0-10)

Domain indicating greatest negative impact on quality of life due to asthma

Domain indicating least negative impact on quality of life due to asthma

Patients who were troubled by shortness of breath in the previous 4 weeks

Shortness of breath that was mildly troubling

Shortness of breath that was severely or very severely troubling

Patient medication adherence (ASK-12-Adherence Starts with Knowledge Questionnaire) ${ }^{27}$

Mean score of ASK-12

Mean subscale score for inconvenience/forgetfulness

Mean subscale score for treatment beliefs

Mean subscale score for behaviour

Patients who did not disagree with the statement that they forgot to take their medication sometimes

Asthma knowledge (CQ-Consumer Asthma Knowledge Questionnaire) ${ }^{28,29}$

Mean score of CQ

Mean domain score for management knowledge

Mean domain score for medication knowledge

Patients who knew that written asthma action plans could prevent hospitalisations

Patients with a lack of understanding about medication side effects

Patient beliefs about asthma control (PCAQ_The Perceived Control of Asthma Questionnaire) ${ }^{30}$

Mean score of PCAQ

Patients who did not disagree with the statement 'It seems as though fate and factors beyond my control affect my asthma'

Patients who agreed or strongly agreed with the statement 'If I do all the right things, I can successfully manage my asthma'
19.1 (s.d. $=4.43$, range $5-25$ )

$$
20
$$

$120(48.4 \%)$

$175(70.6 \%)$

$119(68.0 \%$ of the 175 patients)

$109(44.0 \%)$

$182(73.4 \%)$

1.33 (s.d. $=1.54$, range $0.00-8.57$ )

Social disruption domain mean score 2.10 (s.d. $=1.99$, range $0.00-10.00$ )

Concerns for health domain mean score 1.16

(s.d. = 1.61, range 0.00-9.64)

$172(69.4 \%)$

$102(41.1 \%)$

$17(6.9 \%)$

23.4 (s.d. $=7.16$, range $12-41$ )

6.92 (s.d. $=3.19$, range $3-15$ )

7.96 (s.d. $=7.96$, range 4-17)

8.49 (s.d. $=3.50$, range $5-22$ )

$112(45.2 \%)$

7.29 (s.d. $=1.65$, range $2-10$ )

4.13 (s.d. $=1.17$, range $1-6$ )

3.16 (s.d. $=0.92$, range $0-4$ )

$216(87.1 \%)$

$139(56.1 \%)$

43.0 (s.d. $=5.57$, range $26-55$ )

$102(41.1 \%)$

$221(89.1 \%)$ this through surveying patients in the community pharmacy setting but not targeting any particular subset of patients. In understanding patient need, it was possible to explore how the role of pharmacists can be developed to enhance patient asthma management.

A key finding that warrants further investigation was the discordance between patient perceptions of asthma control and actual asthma control, across the cohort. The significance of these perceptions is that patients are unlikely to proactively seek intervention and support from healthcare professionals in chronic disease management of asthma. They may only access services when experiencing acute exacerbations. Another interesting observation highlighted by the data was that patients had a good understanding of the benefits of written asthma action plans, yet there were low levels of ownership. There was little indication that patients were being proactive in obtaining and using written asthma action plans, despite understanding their importance.

Medication issues were also evident from this survey. There were a significant number of patients with poor asthma control who were using an ICS and, in most instances, also a LABA. Guidelines indicate that most patients can control their asthma symptoms with low-dose ICS. ${ }^{19,31}$ The combination of ICS/LABA is not first-line therapy and is only recommended when medium doses of ICS treatment fail. Given that under-treatment does not seem to be a significant issue related to poor asthma control observed in this cohort, other issues need to be addressed. These could include poor medication adherence, exposure to triggers, symptoms based on co-morbidities, smoking and/or poor inhaler technique. $^{31}$

Although there were a large number of patients being prescribed ICS, there were still over a quarter of patients not using a preventer medication to control their asthma. An explanation for the better control seen in this cohort could be that these patients have less severe disease and hence are able to maintain better control. Nevertheless, there is evidence that patients with persistent asthma but only mild symptoms can benefit from daily ICS treatment. ${ }^{32}$ Meanwhile, the one-third patients not using preventer medication and with poor asthma control are at risk. Excessive use of SABAs has been clearly identified as a risk factor for serious asthma exacerbations and death. ${ }^{19,33}$

A surprising result from this survey was the relatively high proportion of patients who reported having a 'life-threatening' asthma attack in the previous 5 years. Life-threatening attacks refer to an ICU admission or the requirement for mechanical ventilation. ${ }^{19}$ Serious sequelae such as these are rare and in Australia in 2008-2009 the overall age-adjusted rate of invasive mechanical ventilation for asthma was just 13.3 per 1,000 hospital separations for asthma. ${ }^{34}$ The statistic measured could be 


\begin{tabular}{|c|c|c|c|}
\hline Variables & $\begin{array}{l}\text { Odds } \\
\text { ratio }\end{array}$ & $\begin{array}{l}\text { 95\% Confidence } \\
\text { interval }\end{array}$ & P-value \\
\hline \multicolumn{4}{|l|}{ Gender } \\
\hline Female versus male & 1.41 & $0.83-2.40$ & 0.2072 \\
\hline \multicolumn{4}{|l|}{ Age } \\
\hline 1-s.d. increase (19.63 years) & 1.43 & $1.10-1.84$ & 0.0068 \\
\hline \multicolumn{4}{|l|}{ IRSAD } \\
\hline 1 -s.d. increase (39.55 points) & 1.16 & $0.91-1.50$ & 0.2338 \\
\hline \multicolumn{4}{|l|}{ Written asthma action plan } \\
\hline Yes versus no & 1.02 & $0.51-2.01$ & 0.9641 \\
\hline \multicolumn{4}{|l|}{ Overall quality of life score } \\
\hline One-point increase & 22.35 & $9.27-53.88$ & $<0.0001$ \\
\hline \multicolumn{4}{|c|}{ Overall medication adherence scores } \\
\hline One-point increase & 1.00 & $0.96-1.03$ & 0.8098 \\
\hline \multicolumn{4}{|l|}{ Overall asthma knowledge score } \\
\hline One-point increase & 0.98 & $0.84-1.14$ & 0.7955 \\
\hline \multicolumn{4}{|l|}{ Patient beliefs score } \\
\hline One-point increase & 0.89 & $0.84-0.94$ & $<0.0001$ \\
\hline \multicolumn{4}{|l|}{ On ICS medication } \\
\hline Yes versus no & 2.42 & $1.34-4.35$ & 0.0033 \\
\hline \multicolumn{4}{|l|}{ Current smoker } \\
\hline Yes versus no & 2.23 & $1.14-4.36$ & 0.0189 \\
\hline \multicolumn{4}{|l|}{ Hay fever } \\
\hline Yes versus no & 1.28 & $0.77-2.12$ & 0.3410 \\
\hline \multicolumn{4}{|l|}{ Sinusitis } \\
\hline Yes versus no & 2.69 & $1.32-5.49$ & 0.0065 \\
\hline \multicolumn{4}{|l|}{ Combination ICS/LABA } \\
\hline Yes versus no & 1.54 & $0.92-2.57$ & 0.0998 \\
\hline
\end{tabular}

high because it represents the patients' interpretation of 'life-threatening attack'. If this were the case, it demonstrates how vulnerable patients feel when they have an acute exacerbation of symptoms. This cohort also indicated high rates of emergency visits to GPs but relatively low rates of ED presentations and hospitalisation. A possible interpretation is that patients have a poor understanding of the symptoms of asthma and when to seek medical help. Another interesting observation, that should be explored further, was the contradictory nature of the relatively high numbers reporting experience of a 'life-threatening attack,' compared with the overall low concerns for health, indicated by the quality of life assessments. This observation could support the hypothesis that patients are not concerned and do not 'pay attention to their asthma', but panic and are scared when experiencing acute exacerbations.

Interpretation of findings in relation to previously published work In this cohort of community pharmacy patients nearly half of the participants (48.4\%) were assessed as having poorly controlled asthma, which is consistent with other studies in Australia and overseas. $^{35,36}$ It is lower than the $77 \%$ with suboptimal control observed in a cross-sectional study in community pharmacy by Armour and colleagues. ${ }^{11}$ The main difference between the studies is that they were targeting patients for recruitment who were at risk of poor asthma outcomes. The discordance observed in actual asthma control versus perceptions of asthma control was also consistent with much of the literature in Australia ${ }^{37,38}$ and around the world. ${ }^{35,39}$

The accepted issues associated with poorly controlled asthma were also evident from this survey. Patients with poorly controlled asthma were at greater risk of life-threatening attacks, having emergency medical presentations and suffering a reduced quality of life. Contrary to other surveys of asthma patients, no relationships were detected between asthma control and medication adherence and asthma control and rhinitis; however, this may have been due to a lack of power to detect such relationships. The lack of correlation with medication adherence may also have been related to limitations associated with ASK-12 tool, as it is recognised that adherence is difficult to measure. ${ }^{40}$

The ASK-12 is a subjective tool that is reliant on patient memory and willingness to report poor adherence. ${ }^{27}$ Objective measures are the gold standard, and subjective measures are considered less reliable. Problems with reliability were confirmed in validation studies of the ASK-12. The three subscales of the tool were slightly below the accepted cut-offs for reliability (test-retest reliability and internal consistency reliability). It was also noted that reliability might be impacted on in larger samples, because reliability is associated with an upper limit on a scale's validity. ${ }^{27}$ These factors may all have been relevant to the unexpected results.

Despite the lack of correlation in the overall scores, there were indications from the ASK-12 subscale scores that adherence was not ideal. In one question almost half the patients conceded that they forgot to take their medications sometimes. This is consistent with literature reports that around $50 \%$ of patients on long-term therapy fail to take their medication at least some of the time. ${ }^{19}$

It is also well accepted that rhinitis is a co-morbidity that can exacerbate asthma, is frequently under-diagnosed and increasing in prevalence. ${ }^{41}$ The fact that a correlation was not identified in this cohort may also relate to the timing of the survey. Rhinitis is a seasonal condition, and the data collection period for this survey was short and did not coincide with 'hay fever season'. Conversely, the correlations observed in this cohort between asthma control and sinusitis and asthma control and current smoking were consistent with the literature. ${ }^{19}$

The use of written asthma action plans has been recommended in Australian asthma guidelines for more than 20 years, and initiatives have failed to lift ownership levels that remain unacceptably low. The low levels of ownership seen in this cohort were consistent with Australian data from 2007 to 2008. This data reported $14.4 \%$ ownership in persons aged 15 years and over. ${ }^{34}$ In 2013, changes were made to remuneration pathways for GPs, designed to improve chronic disease management and increase levels of written asthma action plan ownership. ${ }^{42}$ However, there is a lack of evidence in this study to demonstrate improvements resulting from these changes.

The medication issues highlighted in this cohort are similar to those in other Australian surveys. In this survey $60 \%$ of participants were using ICS/LABA combination therapy, which implies an overuse of expensive and possibly unnecessary medication. High use has been observed in other Australian studies, albeit at variable levels of $50 \%^{36}$ and $65 \%{ }^{11}$. More disturbing was that this survey and others uncovered a small incidence of LABA use without concomitant ICS treatment. This is contraindicated because of increased risks to morbidity and mortality. The incidence was $0.8 \%$ for this cohort with $0.6 \%^{36}$ and $4 \%{ }^{11}$ in other Australian studies. The high level of ICS in this and other surveys is in contrast to the results from a telephone survey of asthma patients conducted in $2007 .{ }^{38}$ They found the majority (55\%) of 
adult participants were not currently using ICSs, and the figures were even lower in symptomatic patients. The survey also noted that $34 \%$ were managing their asthma with SABAs only, which was notably higher than the result of $22 \%$ for this survey. ${ }^{38}$

In terms of healthcare utilisation, the results from this survey were inconsistent with those from other Australian surveys. Hospitalisation due to asthma has been reported at levels of around $3.7 \%,{ }^{36,38}$ but in this survey the level was $2.8 \%$. Similarly, ED presentations were $10 \%$ in a web-based survey but lower in this cohort at $7.7 \%$. In contrast, a high proportion of patients (47\%) in this survey reported that they had consulted their GP because their asthma was worse or out of control in the previous 12 months, compared with $23 \%$ for the web-based survey. It is likely that these variable results are due to patient interpretation of the questions being asked. In the same web-based survey, 51\% reported having a non-urgent visit to a GP for review of asthma, which correlates with this survey result of $47 \%$. It may be that people in the web-based survey understood the term 'review' as not being related to chronic disease management, but a 'review' of their treatment due to an exacerbation. ${ }^{36}$ Interpretation of survey questions is also likely to have been a factor in patient reports of 'life-threatening exacerbations'.

\section{Strengths and limitations of this study}

A strength of this study is that it was a survey of community-based patients with asthma, visiting a pharmacy but not necessarily seeking advice or assistance with asthma management. Another strength is the comprehensive nature of the survey, utilising five validated tools to provide a complete picture of patient asthma management. Characterisation of patient attributes and needs permits consideration of the current and potential role community pharmacists can have in intervening to improve supported self-management by patients. It also allows for consideration of the appropriateness of current referral pathways. This research will assist in the development of future research interventions being targeted to patient need and the development of formalised roles for pharmacists in asthma management.

A limitation of the study was the low statistical power for some of the subset analysis. However, given the gaps in the literature, this study was regarded as hypothesis generating research to provide a greater understanding of the needs of patients presenting in community pharmacy. Subsequent research will be fully powered to investigate significant findings. Another limitation was the potential for bias in the recruitment of pharmacies and patients for this study. With a convenience sample, generalisability of the results may be limited. The busy retail environment of community pharmacy meant that staff might not have given all patients with asthma presenting in the pharmacy the chance to participate, resulting in staff-selection bias. There was also the possibility of self-selection bias in the sample. Time-poor patients or those working may not have been well represented. Patients who were concerned about their asthma may have been more willing to participate and over-represented. However, it was notable that the demographics were comparable to larger population studies. Another limitation is one associated with many asthma surveys, ${ }^{36}$ the issue that the diagnosis of asthma was self-reported and not confirmed by medical records. Assessments were only made using self-reported data; inhaler technique of patients was not assessed, which may have an impact on asthma control, even when medication adherence is high.

Implications for future research, policy and practice

Based on the Pharmacy Guild of Australia figures, the average community pharmacy encounters about 430 patients a month with asthma. ${ }^{43}$ Extrapolating from the results of the questionnaire, community pharmacies on average would encounter 200 patients with poor asthma control per month or 7 per day. The significant cost of these patients to the community in terms of lost productivity and healthcare utilisation is a burden that community pharmacists have the opportunity to reduce. Recent figures for 2015 indicate a total cost for asthma being \$28bn a year in Australia. ${ }^{44}$ Hospital admissions, ED presentations and emergency GP presentations could all be reduced by early intervention and referral of patients with poor control by community pharmacists. In the financial year 2008-2009, Australia hospital admission costs alone for asthma totalled AUD $\$ 128$ million and out of hospital medical services (primarily services provided by registered medical practitioners) totalled AUD $\$ 198$ million. ${ }^{45}$ Indirect costs associated with lost days off work and study could also be substantially reduced. In 2015, productivity losses due to asthma were estimated to be AUD $\$ 1.1$ billion. ${ }^{44}$

Currently, health service provision in community pharmacy is inconsistent, and prescription dispensing directs the workflow in most community pharmacies. ${ }^{46}$ Guidelines indicate that pharmacists should refer asthma patients to a GP if they are fulfilling the following: experiencing an acute exacerbation; do not own a written asthma action plan; have not had a medical review in the past 6 months; or have been assessed as having poor asthma control. ${ }^{23}$ From our survey results, these criteria would require pharmacists to refer almost every patient with asthma that they encounter. Clearly, this strategy is not achieving the desired results in terms of asthma control, appropriate use of medicines and written asthma action plan ownership. One way to address the issue is to implement programmes to improve guideline compliant referral by pharmacists; however, this does not tackle the barriers faced at the level of the GP. Another option may be to expand the role of pharmacists. Greater recognition and formalisation of the clinical role of pharmacists may facilitate optimisation of the intervention opportunities for pharmacists as primary healthcare professionals. However, there are many barriers to clinical service provision by pharmacists including low patient receptivity, lack of established inter-professional collaborative pathways, time pressures, organisational issues and remuneration pathways that emphasise the sale of product and efficient dispensing, rather than supporting patient-centred health care. ${ }^{46-49}$ Nevertheless, this option seems reasonable to pursue based on pharmacists proven ability to positively have an impact on health outcomes of asthma patients, their high degree of patient accessibility and the demonstrated patient need.

There are several possibilities for expanded practice by pharmacists. Pharmacists could have a role in the development of written asthma action plans for patients. This addresses the current situation whereby patients are not presenting to doctors for written asthma action plans, despite having a sound understanding of their benefit. For pharmacists to undertake this role, further education and training would be required, but given their expertise in medication, it is within their scope of practice. Trials would need to consider how pharmacists could effectively collaborate with the patient's doctor to ensure appropriate medical review for patients.

As medication experts, pharmacists are also well placed to monitor the step-up and step-down medication regimen recommended for asthma to optimise therapy. Asthma, as a variable lung condition, requires continual monitoring and reassessment of dosage and this may not be occurring, especially given the low level of written asthma action plan ownership and the high incidence of LABA prescribing observed. Although pharmacists can identify medication issues, to be truly effective at improving outcomes they need to have the capacity to support guidelinebased treatment and appropriate patient behaviours. This could possibly occur with an expanded prescribing role.

Under-treatment does not seem to be an issue for many patients in this cohort given the high proportion on combination LABA/ICS. Thus, the poor asthma control observed is likely to be 
partly attributed to adherence issues including not using the prescribed medications appropriately or poor device technique, despite not being substantiated by this survey. Along with adherence issues, other explanations for poor control include misdiagnosis and difficult-to-treat asthma. It is likely that only a small proportion would fall into these categories in which case the pharmacist could identify and refer these patients. Convenient access and cost of medication can influence ICS use in asthma patients. ${ }^{31}$ Patients may be prescribed ICS initially, but choose to medicate with cheaper and more accessible SABAs, particularly when required to see a GP to obtain on-going ICS prescriptions. They may have a poor understanding of the concept of 'preventer' treatments and preferentially choose the treatment that provides obvious and immediate symptomatic relief. 'Continued Dispensing' is a novel way that pharmacists could contribute to solving these barriers. The Pharmaceutical Society of Australia released 'Guidelines for the Continued Dispensing of eligible prescribed medicines by pharmacists V1.0' in January 2012. ${ }^{50}$ This new legislation allows pharmacists to use their professional judgement to maintain supply of certain medications and ensure continuity of therapy. In this way, pharmacists may intervene when patients seek to self-medicate with SABAs by offering education and a continued supply of ICS. A trial of Continued Dispensing of ICS could be considered given the results of this survey indicating high levels of ICS prescribing but still inadequate asthma control. However, any such trial would need to consider potential detrimental effects to the recommended 6-monthly medical review of patients.

Medication adherence issues are also a key area that pharmacists could have an impact on. Community pharmacists can easily monitor medication adherence via dispensing software. Studies have demonstrated the potential of computer-generated prompts in facilitating pharmacist intervention. ${ }^{51-53}$ The regular contact pharmacists have with patients provides the opportunity for discussion of the complexities that underlie non-adherent behaviour. However, deciphering patient beliefs requires time and advanced communication skills, using patient-centred counselling techniques. Pharmacists may require skills training to undertake more in-depth, motivational style interviewing. Such activities are also labour intensive, and time and resources can also only be allocated given appropriate remuneration.

Although remuneration is an important barrier, it is not the only determinant in pharmacist participation in clinical services, and remuneration alone will not ensure successful uptake. ${ }^{54}$ Inhaler device technique checks are an example that demonstrates this issue. Remuneration has recently become available for pharmacists in Australia for inhaler technique checking, ${ }^{55}$ and this may improve uptake into practice, although other significant barriers to practice change have not been addressed. Workflows based around dispensing and pharmacy layouts possibly contribute to the difficulties in re-organisation of practice to accommodate clinical services and longer patient consultations. ${ }^{49}$ Patient perceptions and receptivity may also be relevant. A lack of expectation of a service may lead to resistance by patients to participate or lack of motivation by pharmacists to provide the service. ${ }^{46,49}$ Multiple expanded services and remuneration options in asthma could provide the necessary incentive to undertake the organisational and capacity changes required. It could also expedite changes in patient perceptions and expectations from a pharmacy consultation. Currently, one of the issues pharmacists have with the non-prescription supply of SABAs are the patient barriers encountered. In a retail environment, patients have a sense of entitlement; they perceive that the medication is safe and do not expect to be asked questions. ${ }^{9}$ These communication issues are further exacerbated and problematic if patients have poor perceptions around asthma control. There are many areas in asthma management and patient care that pharmacists already participate in or could expand their practice to incorporate.
These include improving inhaler technique, facilitating smoking cessation and providing holistic patient care by addressing co-morbidities that influence asthma such as rhinitis, sinusitis and depression. The key may be expanding and formalising the pharmacists' role in asthma to improve the viability of services and ensure consistency of care.

\section{Conclusions}

Pharmacists have the potential to optimise asthma management in the community by direct intervention. Nearly, half of the participants surveyed were assessed as having poorly controlled asthma, yet a proportion of patients displayed a lack of awareness of the issue and were thus unlikely to be seeking support from a health professional. Their poor control had them at risk of life-threatening attacks, requiring emergency medical care and experiencing a reduced quality of life. There is scope to investigate pharmacists preparing written asthma action plans for patients, using software to monitor medication adherence and prescribing on-going medications for asthma, to improve guideline-based management. To maximise the potential of pharmacists, barriers to practice need to be identified and addressed.

\section{MATERIALS AND METHODS}

Ethics

Ethics approval was obtained from the University of Western Australia's Human Research and Ethics Committee (HREC RA/4/1/5000) for both the pilot and cross-sectional study. Written informed consent was obtained from all participants in this research.

\section{Questionnaire development}

A questionnaire was designed by the research team to comprehensively characterise patients and their asthma management in the primary healthcare setting. Demographic and patient history questions were based on epidemiological data available in Australia. ${ }^{34,56} \mathrm{~A}$ review of the literature was undertaken to investigate current, validated tools available. Of primary interest were review articles that provided a comparison and critical appraisal of available tools or recommended a gold standard. ${ }^{40,57-62}$ Also of interest were tools previously used in an Australian setting. Several tools were selected for incorporation into a composite Asthma Questionnaire (Supplementary Appendix 1-Final composite asthma questionnaire-Validated tools included and scoring). Where necessary, licences to use the selected tools were obtained before commencement of study. The finalised Asthma Questionnaire was formatted into a scannable document to improve readability and simplify data entry (Supplementary Appendix 2-Questionnaire). A medication sheet was devised to complement the Asthma Questionnaire and record patients' current medications. Endorsement of the questionnaire was sought and obtained from the National Secretariat of The Pharmacy Guild of Australia. The questionnaire was given an $\mathrm{A} 1$ rating as part of the Survey Approval Program of The Pharmacy Guild of Australia (certificate number 819). ${ }^{63}$

\section{Pilot study}

A pilot study was conducted in a community pharmacy in Perth, Western Australia, between March and May 2012. The aim was to assess the ease of recruiting participants with asthma from community pharmacies and the utility of the new composite Asthma Questionnaire. The pilot identified that patient recruitment was a challenge. Feedback from pharmacy staff and researcher assistants indicated that the length of the questionnaire was a barrier to patient involvement. Researcher assistants administering the questionnaire reported that patients had difficulties in completing the 60-item knowledge section (KASE-AQ-Knowledge, Attitude, and Self-Efficacy Asthma Questionnaire), ${ }^{64}$ and that it substantially added to the time to complete the Asthma Questionnaire.

Modifications based on pilot study

Changes were made to patient recruitment methodology and to the composite Asthma Questionnaire based on the results of the pilot study. A multimodal method of recruitment was devised to reduce the burden of 


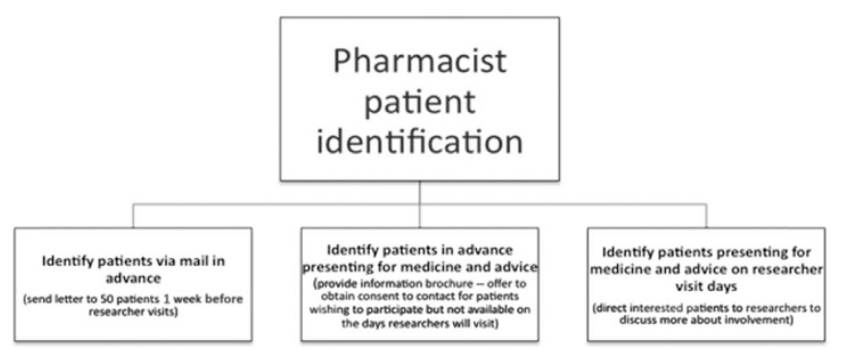

Figure 1. Patient recruitment diagram.

recruitment on pharmacy staff and to increase the speed of recruitment. Patients were reimbursed for their time. The 60-item KASE-AQ knowledge tool was initially selected for the composite questionnaire based on recommendation in a review article. ${ }^{62}$ It was changed to a more recently developed and shorter tool, the 10-item Consumer Asthma Knowledge Questionnaire (CQ). ${ }^{29}$ The CQ was not originally chosen for the pilot questionnaire due to criticisms raised about an earlier 12 -item version. ${ }^{62}$ The authors of the CQ were contacted to obtain more information about the refined 10-item CQ and to respond to the review criticisms that were satisfactorily addressed. Apart from its brevity, another advantage of the CQ over the KASE-AQ was that it was developed by researchers at the University of Sydney and thus highly applicable to the Australian context. ${ }^{29}$

\section{Cross-sectional survey}

The refined composite Asthma Questionnaire was administered as a semistructured, cross-sectional survey, to patients with asthma, recruited from community pharmacies. The survey was administered to patients between March and May 2013.

\section{Sample size}

The feasibility of patient recruitment was based on information from the Pharmacy Guild Digest that each community pharmacy services on average a population of 4,300 people. ${ }^{43}$ With $10 \%$ of the population currently reported to suffer from asthma in Australia ${ }^{34,45}$ that means that each pharmacy provided service to $\sim 430$ people with asthma. On average patients visited their community pharmacy about once per month. ${ }^{43}$ Thus, in a 2-week period, an estimate of 215 patients with asthma attended their community pharmacy. Assuming $5 \%$ recruitment resulted in a feasibility of 10 patients interviewed per pharmacy over the study period. This number was deemed appropriate and achievable given the resources available for the study. However, it should be noted that no formal priori sample size calculation was carried out.

\section{Research assistant training}

Master of Pharmacy students from the University of Western Australia acted as research assistants to administer questionnaires. They were provided initial training on ethics requirements, background information about asthma, guidelines and validated tools and how to administer the questionnaire. Weekly meetings were held throughout the data collection period to discuss any issues encountered. Research assistants sat with patients as they filled in the questionnaire and could clarify questions but only when patients asked for assistance. For instance, patients were only given definitions of 'life-threatening asthma' and 'written asthma action plan' if they specifically asked, thus their perception of these concepts was the basis for answers. Research assistants completed the medication sheet with information provided by patients. Following completion of the questionnaire, patients were asked if they had any questions. The research assistants were permitted to offer clinical advice within their capabilities as final year Masters students or could refer the patients back to the pharmacist in store.

\section{Pharmacy recruitment and training}

A convenience sample of community pharmacies, in the north metropolitan area of Perth, Western Australia, was invited to participate in the research as patient recruitment sites. Comparisons based on pharmacy type and pharmacy location were undertaken to check for potential non-response bias. A researcher visited each pharmacy to explain the methodology prior to commencement of the study. A PowerPoint presentation and instruction sheet was used as part of the training. Banners and brochures were also developed to facilitate recruitment and promote the research in store. Research assistants were individually allocated to a pharmacy at set times over a 2-week period for patient interviews and data collection.

\section{Patient recruitment and inclusion criteria}

In response to the pilot study, three different recruitment methods were offered to pharmacists to encourage pharmacy participation and to maximise patient interview numbers as per Figure 1. Only one pharmacy decided to send out letters. Most recruitment was by provision of information brochures and incidentally when researchers were in store, where the banners attracted attention. Ethics requirements determined that researchers could not approach patients directly, which added to the challenge of recruitment. Pharmacy staff were instructed to offer interviews to any patient with asthma presenting to the pharmacy. The aim was to schedule interview appointments for at least 10 asthma patients over the 2-week researcher visit. Patient eligibility was based on the following three inclusion criteria: People diagnosed with asthma who were over 18 years of age and able to speak and read English.

\section{Data analysis}

Demographics and medical history were collated and tabulated. Each of the validated tools was scored individually. Summary statistics, including means, s.d., medians, maximums, minimums as well as percentages and counts were calculated for each question and for each tool's summary score. Binary logistic regression was used to analyse relationships between questionnaire responses and poor asthma control, ICS use, ownership of a written asthma action plan as well as medical presentation and life-threatening attack in the past 5 years (event = 'yes' for all the analyses). ORs and $95 \% \mathrm{Cls}$ are provided. General linear regression was used to model (log-transformed) quality of life and (log-transformed) medication adherence and their relationships with patient demographics. Using participants' postcodes, an Index of Relative Socio-economic Advantage and Disadvantage (IRSAD) value was assigned to each participant. The IRSAD was collected in the 2011 Census of Population and Housing, and is one of the Social Indexes for Areas. ${ }^{65}$ Patient age, sex and IRSAD score were adjusted for in all analyses. For all analyses, variables that were significant at the $5 \%$ level were retained in the final model. All data were analysed using the $\mathrm{R}$ environment for statistical computing. ${ }^{66}$

\section{ACKNOWLEDGEMENTS}

We are grateful to the community pharmacies and their patients with asthma who agreed to participate in this research, along with the Master of Pharmacy students from the University of Western Australia who administered the questionnaires. We would also like to acknowledge Jeanette McQueen and the staff at SAVANT surveys for their assistance in formatting and scanning the questionnaires.

\section{CONTRIBUTIONS}

KW conceptualised and designed this research as part of her PhD studies, guided and supervised by CS, KM, PK and RC. KW and RC secured funding for the research from the Health Department of Western Australia. AB assisted KW with literature searches for appropriate validated tools for the development of the questionnaire. KW developed the questionnaire. MT and KM completed the statistical analysis with input from KW. KW prepared an initial draft paper with all authors contributing to subsequent drafts and approving the final manuscript.

\section{COMPETING INTERESTS}

KW is the proprietor of a community pharmacy in Perth, Western Australia, and thus has a financial interest in community pharmacy. The remaining authors declare no conflict of interest.

\section{FUNDING}

$\mathrm{KW}$ is the recipient of an unrestricted PhD scholarship from AstraZeneca and a grant from the Health Department of Western Australia. There are no further funding arrangements for this research. 


\section{REFERENCES}

1. Berger, W. E. New approaches to managing asthma: a US perspective. Ther. Clin. Risk Manag. 4, 363-379 (2008).

2. The Global Asthma Network. The Global Asthma Report (Auckland, New Zealand, 2014).

3. Australian Institute of Health and Welfare. National Health Priority Areas (2016).

4. Barton, C. et al. Management of asthma in Australian general practice: care is still not in line with clinical practice guidelines. Prim. Care Respir. J. 18, 100-105 (2009).

5. Yawn, B. P. The role of the primary care physician in helping adolescent and adult patients improve asthma control. Mayo Clin. Proc. 86, 894-902 (2011).

6. Wiener-Ogilvie, S. et al. Do practices comply with key recommendations of the British Asthma Guideline? If not, why not? Prim. Care Respir. J. 16, 369-377 (2007).

7. Backer, V., Bornemann, M., Knudsen, D. \& Ommen, H. Scheduled asthma management in general practice generally improve asthma control in those who attend. Respir. Med. 106, 635-641 (2012).

8. Pinnock, H. \& Sheikh, A. Primary care research and clinical practice: respiratory disease. Postgrad. Med. J. 85, 74-79 (2009).

9. Watkins, K., Fisher, C., Misaghian, J., Schneider, C. R. \& Clifford, R. A qualitative evaluation of the implementation of guidelines and a support tool for asthma management in primary care. Asthma Res. Pract. (e-pub ahead of print 4 May 2016; doi: 10.1186/s40733-016-0023-9).

10. International Pharmaceutical Federation. Global Pharmacy: Workforce Report. 92. (The Hague, 2009).

11. Armour, C. L. et al. Using the community pharmacy to identify patients at risk of poor asthma control and factors which contribute to this poor control. J. Asthma 48, 914-922 (2011).

12. Bosnic-Anticevich, S. Z. Asthma management in primary care: caring, sharing and working together. Eur. Respir. J. 47, 1043-1046 (2016).

13. Armour, C. et al. Pharmacy Asthma Care Program (PACP) improves outcomes for patients in the community. Thorax 62, 496-502 (2007).

14. Bereznicki, B. J. et al. Pharmacist-initiated general practitioner referral of patients with suboptimal asthma management. Pharm. World Sci. 30, 869-875 (2008).

15. Fathima, M., Naik-Panvelkar, P., Saini, B. \& Armour, C. L. The role of community pharmacists in screening and subsequent management of chronic respiratory diseases: a systematic review. Pharm. Pract. 11, 228-245 (2013).

16. Garcia-Cardenas, V. et al. Pharmacists' interventions on clinical asthma outcomes: a systematic review. Eur. Respir. J. 47, 1134-1143 (2016).

17. Schneider, C. R., Everett, A. W., Geelhoed, E., Kendall, P. \& Clifford, R. M. Measuring the assessment and counselling provided with the supply of non-prescription asthma reliever medication: a simulated patient study. Ann. Pharmacother. $\mathbf{4 3}$, 1512-1518 (2009).

18. Schneider, C. R. et al. Provision of primary care to patients with chronic cough in the community pharmacy setting. Ann. Pharmacother. 45, 402-408 (2011).

19. Global Initiative for Asthma (GINA). Global Strategy for Asthma Management and Prevention. (Bethesda, MD, USA, 2015).

20. Kritikos, V. S., Reddel, H. K. \& Bosnic-Anticevich, S. Z. Pharmacists' perceptions of their role in asthma management and barriers to the provision of asthma services. Int. J. Pharm. Pract. 18, 209-216 (2010).

21. Wiener-Ogilvie, S., Huby, G., Pinnock, H., Gillies, J. \& Sheikh, A. Practice organisational characteristics can impact on compliance with the BTS/SIGN asthma guideline: qualitative comparative case study in primary care. BMC Fam. Pract. 9, 32 (2008).

22. Government of Western Australia. Department of Health. Poisons Regulations 1965. Vol. 2013 (State Law Publisher, 1965).

23. Pharmaceutical Society of Australia (PSA). Guidance for the provision of a Phar macist Only medicine; short-acting beta-agonists (salbutamol and terbutaline) Canberra (2012). Available from: http://www.psa.org.au/download/guidelines/ Short-acting-beta-antagonist-protocol.pdf.

24. Nathan, R. A. et al. Development of the asthma control test: a survey for assessing asthma control. J. Allergy Clin. Immunol. 113, 59-65 (2004).

25. Schatz, M. et al. Asthma Control Test: Reliability, validity, and responsiveness in patients not previously followed by asthma specialists. J. Allergy Clin. Immunol. 117, 549-556 (2006).

26. Marks, G. B., Dunn, S. M. \& Woolcock, A. J. A scale for the measurement of quality of life in adults with asthma. J. Clin. Epidemiol. 45, 461-472 (1992).

27. Matza, L. S. et al. Derivation and validation of the ASK-12 adherence barrier survey. Ann. Pharmacother. 43, 1621-1630 (2009).

28. Kritikos, V., Krass, I., Chan, H. S. \& Bosnic-Anticevich, S. Z. The validity and reliability of two asthma knowledge questionnaires. J. Asthma 42, 795-801 (2005).

29. Saini, B. et al. Asthma disease management-Australian pharmacists interventions improve patients' asthma knowledge and this is sustained. Patient Educ. Couns. 83, 295-302 (2011).
30. Katz, P. P., Yelin, E. H., Eisner, M. D. \& Blanc, P. D. Perceived control of asthma and quality of life among adults with asthma. Ann. Allergy Asthma Immunol. 89, 251-258 (2002).

31. National Asthma Council Australia (NAC). Australian Asthma Handbook 2015 Version 1.1. (National Asthma Council Australia, Melbourne, 2015). Available from: http://www.asthmahandbook.org.au.

32. O'Byrne, P. M. et al. Low dose inhaled budesonide and formoterol in mild persistent asthma: The OPTIMA randomized trial. Am. J. Respir. Crit. Care Med. 164, 1392-1397 (2001).

33. Levy, M. L. The national review of asthma deaths: What did we learn and what needs to change? Breathe 11, 15-24 (2015).

34. Australian Centre for Asthma Monitoring. Asthma in Australia 2011: With a Focus Chapter on Chronic Obstructive Pulmonary Disease. Vol. 2012 (AlHW, 2011). Available from: http://www.aihw.gov.au/publication-detail/?id=10737420159.

35. Price, D., Fletcher, M. \& van der Molen, T. Asthma control and management in 8,000 European patients: the REcognise Asthma and LInk to Symptoms and Experience (REALISE) survey. npj Prim. Care Respir. Med. 24, 1409 (2014). Available from: MEDLINE.

36. Reddel, H. K., Sawyer, S. M., Everett, P. W., Flood, P. V. \& Peters, M. J. Asthma control in Australia: a cross-sectional web-based survey in a nationally representative population. Med. J. Aust. 202, 492-497 (2015).

37. National Asthma Council Australia (NAC), Asthma Australia, The Woolcock Institute of Medical Research \& Pharmacy Guild of Australia. Short on Air Report (2010).

38. Marks, G. B. et al. Asthma management and outcomes in Australia: a nation-wide telephone interview survey. Respirology 12, 212-219 (2007).

39. Murphy, K. R. et al. Asthma management and control in the United States: results of the 2009 asthma insight and management survey. Allergy Asthma Proc. 33, 54-64 (2012)

40. Shi, L. et al. Concordance of adherence measurement using self-reported adherence questionnaires and medication monitoring devices. Pharmacoeconomics 28, 1097-1107 (2010).

41. Egan, M. \& Bunyavanich, S. Allergic rhinitis: the 'Ghost Diagnosis' in patients with asthma. Asthma Res. Pract. 1, 1-7 (2015).

42. Australian Government Department of Human Services. Practice Incentives Program: Asthma Incentive Guidelines (Canberra: Medicare) (2012). Available from: http://www.google.com.au/search?client=safari\&rls=en\&q=Australian+govern ment+practice+incentives+asthma\&ie=UTF-8\&oe=UTF-8\&gfe_rd=cr\&ei=skY fWLHbJ7LM8gfo353YBw.

43. Pharmacy Guild of Australia. Guild Digest (2012)

44. National Asthma Council of Australia (NAC). The Hidden Cost of Asthma. Deloitte Access Economics Pty Ltd; 2015. Available from: http://www2.deloitte.com/au/en/ pages/economics/articles/hidden-cost-asthma.html

45. Australian Institute of Health and Welfare. Asthma Canberra: Commonwealth of Australia. Available from: http://www.aihw.gov.au/asthma/.

46. Blalock, S. J., Roberts, A. W., Lauffenburger, J. C., Thompson, T. \& O'Connor, S. K. The effect of community pharmacy-based interventions on patient health outcomes: a systematic review. Med. Care Res. Rev. 70, 235-266 (2013).

47. Jones, E. J., Mackinnon, N. J. \& Tsuyuki, R. T. Pharmaceutical care in community pharmacies: practice and research in Canada. Ann. Pharmacother. 39, 1527-1533 (2005).

48. Pronk, M., Blom, L., Jonkers, R. \& Bakker, A. Community pharmacy and patientoriented activities: the Dutch case. Patient Educ. Couns. 46, 39-45 (2002).

49. Roberts, A. S., Benrimoj, S. I., Chen, T. F., Williams, K. A. \& Aslani, P. Practice change in community pharmacy: quantification of facilitators. Ann. Pharmacother. 42, 861-868 (2008)

50. Pharmaceutical Society of Australia (PSA). Guidelines for the Continued Dispensing of eligible prescribed medicines by pharmacists V1.0. 7 Dec 2015 (2012).

51. Watkins, K., Wood, H., Schneider, C. R. \& Clifford, R. Effectiveness of implementation strategies for clinical guidelines to community pharmacy: a systematic review. Implement. Sci. 10, 151 (2015).

52. Curtain, C., Peterson, G. M., Tenni, P., Bindoff, I. K. \& Williams, M. Outcomes of a decision support prompt in community pharmacy-dispensing software to promote step-down of proton pump inhibitor therapy. Br. J. Clin. Pharmacol. 71, 780-784 (2011).

53. Reeve, J. F., Tenni, P. C. \& Peterson, G. M. An electronic prompt in dispensing software to promote clinical interventions by community pharmacists: a randomized controlled trial. Br. J. Clin. Pharmacol. 65, 377-385 (2008).

54. Houle, S. K., Grindrod, K. A., Chatterley, T. \& Tsuyuki, R. T. Paying pharmacists for patient care: A systematic review of remunerated pharmacy clinical care services. Can. Pharm. J. 147, 209-232 (2014).

55. Pharmacy Guild of Australia. Inhaler Technique Check Protocol (GuildLink, 2015).

56. Australian Centre for Asthma Monitoring. Survey questions for monitoring national asthma indicators (AlHW, 2007). 
57. Halbert, R. J., Tinkelman, D. G., Globe, D. R. \& Lin, S.-L. Measuring asthma control is the first step to patient management: a literature review. J. Asthma 46, 659-664 (2009).

58. Revicki, D. \& Weiss, K. B. Clinical assessment of asthma symptom control: review of current assessment instruments. J. Asthma 43, 481-487 (2006).

59. Apfelbacher, C. J., Hankins, M., Stenner, P., Frew, A. J. \& Smith, H. E. Measuring asthma-specific quality of life: structured review. Allergy 66, 439-457 (2011).

60. Bender, B., Milgrom, H. \& Apter, A. Adherence intervention research: what have we learned and what do we do next? J. Allergy Clin. Immunol. 112, 489-494 (2003).

61. Lavsa, S. M., Holzworth, A. \& Ansani, N. T. Selection of a validated scale for measuring medication adherence. J. Am. Pharm. Assoc. (2003) 51, 90-94 (2011)

62. Pink, J., Pink, K. \& Elwyn, G. Measuring patient knowledge of asthma: a systematic review of outcome measures. J. Asthma 46, 980-987 (2009).

63. Pharmacy Guild of Australia. Policies and Position Statement: Industry Surveys (Canberra, 2011)

64. Wigal, J. K. et al. The knowledge, attitude, and self-efficacy asthma questionnaire. Chest 104, 1144-1148 (1993).
65. Pink, B. Census of Population and Housing: Socio-Economic Indexes for Areas (SEIFA) Technical Paper (Australian Bureau of Statistics, 2011). Available from: http://www. abs.gov.au/ausstats/abs@.nsf/Lookup/by\%20Subject/2033.0.55.001 2011 Main \%20Features Technical\%20Paper 5.

66. $\mathrm{R}$ Core Team. R: A language and environment for statistical computing (Vienna, Austria, 2015)

\section{cc) (i)}

This work is licensed under a Creative Commons Attribution 4.0 International License. The images or other third party material in this article are included in the article's Creative Commons license, unless indicated otherwise in the credit line; if the material is not included under the Creative Commons license, users will need to obtain permission from the license holder to reproduce the material. To view a copy of this license, visit http://creativecommons.org/licenses/ by/4.0/

(c) The Author(s) 2016

Supplementary Information accompanies the paper on the npj Primary Care Respiratory Medicine website (http://www.nature.com/npjpcrm) 